\title{
Diagnostic Values of Some Fibrinolytic Indicators for Rejecting the Presence of Paroxysmal Atrial Fibrillation
}

\author{
Krasimira Prodanova, Mariya Negreva, Katerina Vitlianova
}

\begin{abstract}
Diagnostic tests are a cornerstone in modern medicine. They are used not only to confirm the presence of a disease but also to rule out the disease in healthy subjects. Tests with two outcome categories (i.e. presence/absence) are known as dichotomous tests. Their inherent validity is determined by sensitivity and specificity and the receiver operating characteristic (ROC) curve is known to be a simple, yet complete plot that displays the full picture of trade-off between the sensitivity (true positive rate) and (1- specificity) (false positive rate) across a series of cut-off points. Our study found that, even in the early hours of paroxysmal atrial fibrillation, there were significant changes in major indicators of fibrinolysis, namely plasminogen level, $t$-PA level, PAI-1 activity, a2-antiplasmin activity, vitronectin and D-dimer plasma levels. We believe that they are closely related and stem from the disease itself. This gave us reason, using these indicators as predictors, to search for a diagnostic option to rule out PAF. We used statistical models of logistic regression analysis and ROC to achieve this. Values of $p<0.05$ were considered statistically significant. Plasma levels of vitronectin have been found to be the most reliable predictor for ruling out PAF (specificity $88 \%$, sensitivity 83\%, AUC 0.96), while D-dimer levels had the lowest diagnostic values (37\% specificity, $81 \%$ sensitivity, AUC 0.56). The obtained results are not only of pure scientific but also of applied nature. They could be used to improve identification of patients at risk for PAF embolism, and assist in the choice of thromboprophylaxis.

Keywords: paroxysmal atrial fibrillation, fibrinolytic markers, logistic regression analysis, receiver operating characteristics.
\end{abstract}

\section{INTRODUCTION}

\section{$\mathrm{P}$} aroxysmal atrial fibrillation (PAF) affects 20\%-30\% of patients with atrial fibrillation (AF) [1]. PAF has specific manifestation features. It occurs in younger patients (decades 40-49, 50-59, and 60-69 years), who have fewer concomitant cardiac and extra-cardiac diseases. The episodes can be very short, run asymptomatically, and therefore often overlooked by the patients themselves. It is difficult to determine its actual incidence. According to some epidemiological studies,

* Correspondence Author

Krasimira Prodanova, B.Sc: Technical University of Sofia, Faculty of applied mathematics and informatics, Sofia, Bulgaria; kprod@tu-sofia.bg

Mariya Negreva*, Department of Cardiology, Medical University of Varna, First clinic of cardiology, Varna University Hospital "St. Marina", Varna, Bulgaria; mnegreva@abv.bg

Katerina Vitlianova, Clinic of Cardiology, Second City Hospital of Sofia, Sofia, Bulgaria; k.vitlianova@abv.bg

(C) The Authors. Published by Blue Eyes Intelligence Engineering and Sciences Publication (BEIESP). This is an open access article under the CC BY-NC-ND license (http://creativecommons.org/licenses/by-nc-nd/4.0/)
Revised Manuscript Received on April 20, 2019.

PAF is asymptomatic much more frequently than other types of atrial fibrillation - up to $81 \%$ of cases [2].

These clinical manifestation specifics are the reason for the disease to be frequently undiagnosed and to skip anticoagulant therapy [3]. At the same time, somewhat surprisingly given the generally mild clinical course, strokes are not uncommon. A large retrospective study by Banerjee et al. of over 7000 patients showed that the risk of stroke in patients with paroxysmal, persistent, and permanent atrial fibrillation is similar and independent of arrhythmia duration [4]. Similar results have been found in other large studies [5], [6]. Paciaroni et al. even showed that there was no significant difference in the incidence of recurrent cardiovascular events in patients with paroxysmal and non-paroxysmal atrial fibrillation [7]. PAF is considered to be a major cause of cryptogenic strokes. In the SURPRISE study, atrial fibrillation paroxysms were detected in every fifth cryptogenic stroke at a markedly low duration of episodes between 1 and 4 hours [8]. Wohlfahrt $\mathrm{J}$ et al. determined an even higher frequency and identified every third cryptogenic stroke as a consequence of PAF [9]. Therefore, despite its short duration, the disease should not be underestimated. The frequently asymptomatic course of the disease necessitates the search for laboratory biomarkers to improve and facilitate diagnosis.

In our clinical trial of PAF patients, we found significant changes in major indicators of fibrinolysis as early as the first twenty-four hours of the clinical manifestation of the arrhythmia (Table 1) [10].

The summary analysis of the results showed that short episodes of the disease (duration $<24$ hours) were associated with increased fibrinolytic activity due to activated coagulation. The absence of a statistically significant difference between patient and control groups in terms of gender, age, accompanying diseases and treatment, as well as in terms of ultrasound indicators LA volume, LV size and systolic function and RVEDD (Table 2, Table 3) gave us reason to accept that the changes in fibrinolytic indicators were due to the rhythmic disturbance itself, and not to "co-existing factors".

Therefore we thought it appropriate to search for reliable markers for the diagnosis of PAF among these indicators.

Published By: 
Table 1. Fibrinolytic markers in patients with PAF and controls in sinus rhythm (results from our previous

study).

\begin{tabular}{|l|l|l|l|}
\hline $\begin{array}{l}\text { Fibrinolytic } \\
\text { markers }\end{array}$ & Patients & Controls & P values \\
\hline $\begin{array}{l}\text { Plasminogen } \\
\text { levels (\%) }\end{array}$ & $159.40 \pm 4.81$ & $100.2 \pm 2.88$ & $\mathrm{p}<0.001$ \\
\hline $\begin{array}{l}\mathrm{t}-\mathrm{PA} \text { level } \\
\text { (ng/mL) }\end{array}$ & $11.25 \pm 0.35$ & $6.05 \pm 0.31$ & $\mathrm{p}<0.001$ \\
\hline $\begin{array}{l}\text { PAI-1 activity } \\
\text { (AU/mL) }\end{array}$ & $7.33 \pm 0.37$ & $15.15 \pm 0.52$ & $\mathrm{p}<0.001$ \\
\hline $\begin{array}{l}\alpha 2 \text {-antiplasmin } \\
\text { activity (\%) }\end{array}$ & $112.9 \pm 2.80$ & $125.60 \pm 3.74$ & $\mathrm{p}<0.05$ \\
\hline $\begin{array}{l}\text { Vitronectin } \\
\text { (mcg/mL) }\end{array}$ & $134.7 \pm 5.83$ & $287.3 \pm 10.44$ & $\mathrm{p}<0.001$ \\
\hline D-dimer (mg/L) & $0.53 \pm 0.07$ & $0.33 \pm 0.02$ & $\mathrm{p}<0.05$ \\
\hline
\end{tabular}

Table 2. Clinical characteristics of patient and control groups.

\begin{tabular}{|c|c|c|c|}
\hline & $\begin{array}{l}\text { Patients } \\
\text { with PAF }\end{array}$ & $\begin{array}{l}\text { Control } \\
\text { group }\end{array}$ & $P$ values \\
\hline $\begin{array}{l}\text { Number } \\
\text { participants in the } \\
\text { group }\end{array}$ & 51 & 52 & $\mathrm{p}=0.89$ \\
\hline Mean age (years) & $59.84 \pm 1.60$ & $59.50 \pm 1.46$ & $\mathrm{p}=0.87$ \\
\hline Men/Women & $26 / 25$ & $26 / 26$ & $\mathrm{p}=1 / \mathrm{p}=0.93$ \\
\hline $\begin{array}{l}\text { Accompanying } \\
\text { diseases } \\
\text { Hypertension } \\
\text { Diabetes mellitus type } \\
2\end{array}$ & $\begin{array}{l}37 \\
(72.54 \%) \\
3(5.88 \%)\end{array}$ & $\begin{array}{l}34 \\
(65.38 \%) \\
2(3.84 \%)\end{array}$ & $\begin{array}{l}p=0.44 \\
p=0.62\end{array}$ \\
\hline Dyslipidemia & 4 (7.84\%) & 3 (5.77\%) & $\mathrm{p}=0.69$ \\
\hline $\begin{array}{l}\text { Medicaments for } \\
\text { Hypertension and } \\
\text { Dyslipidemia } \\
\text { Beta blockers } \\
\text { ACE inhibitors } \\
\text { Sartans } \\
\text { Statins }\end{array}$ & $\begin{array}{l}19 \\
(37.25 \%) \\
15 \\
(29.41 \%) \\
11 \\
(21.57 \%) \\
4(7.84 \%)\end{array}$ & $\begin{array}{l}17 \\
(32.69 \%) \\
14 \\
(26.92 \%) \\
9(17.31 \%) \\
3(5.77 \%)\end{array}$ & $\begin{array}{l}p=0.62 \\
p=0.78 \\
p=0.58 \\
p=0.69\end{array}$ \\
\hline $\begin{array}{l}\text { Deleterious habits } \\
\text { Smoking } \\
\text { Alcohol intake } \\
\end{array}$ & $\begin{array}{l}8(15.69 \%) \\
7(13.72 \%) \\
\end{array}$ & $\begin{array}{l}7(13.46 \%) \\
6(11.53 \%) \\
\end{array}$ & $\begin{array}{l}\mathrm{p}=0.75 \\
\mathrm{p}=0.74\end{array}$ \\
\hline BMI $\left(\mathbf{k g} / \mathrm{m}^{2}\right)$ & $23.85 \pm 0.46$ & $24.95 \pm 0.45$ & $p=0.09$ \\
\hline
\end{tabular}

Table 3. Echocardiographic parameters of the participants.

\begin{tabular}{|l|l|l|l|}
\hline & $\begin{array}{l}\text { Patients } \\
\text { with PAF }\end{array}$ & $\begin{array}{l}\text { Control } \\
\text { group }\end{array}$ & $\begin{array}{l}\text { P } \\
\text { values }\end{array}$ \\
\hline $\begin{array}{l}\text { Echocardiographic } \\
\text { indicators }\end{array}$ & & & \\
\hline LVEDD (mm) & $52.57 \pm 0.58$ & $52.29 \pm 0.57$ & $\mathrm{p}=0.73$ \\
\hline LVESD (mm) & $34.43 \pm 0.56$ & $34.73 \pm 0.48$ & $\mathrm{p}=0.69$ \\
\hline EF (\%) & $62.98 \pm 0.70$ & $61.54 \pm 0.58$ & $\mathrm{p}=0.12$ \\
\hline IVS (mm) & $10.37 \pm 0.23$ & $9.92 \pm 0.26$ & $\mathrm{p}=0.20$ \\
\hline PW (mm) & $10.24 \pm 0.21$ & $9.73 \pm 0.28$ & $\mathrm{p}=0.16$ \\
\hline LA volume (ml/m²) & $22.81 \pm 0.45$ & $23.82 \pm 0.48$ & $\mathrm{p}=0.13$ \\
\hline RVEDD (mm) & $30.54 \pm 1.58$ & $29.17 \pm 1.52$ & $\mathrm{p}=0.18$ \\
\hline
\end{tabular}

\section{MATERIALS}

\section{Study population and design}

The study was conducted at the Intensive Cardiology Unit of the First Cardiology Clinic at the University Hospital St. Marina • Varna for the period October 2010 - May 2012, after approval by the Research Ethics Committee (9/14.10.2010) at the same hospital and in accordance with the requirements of the Declaration of Helsinki [11].

51 non-anticoagulated PAF patients (26 men, 25 women, aged $59.84 \pm 1.60$ years) and 52 controls without anamnestic or electrocardiographic AF data to date (26 men, 26 women, aged $59.50 \pm 1.46$ years) were sequentially selected for the study, corresponding in terms of gender, age, BMI, co-morbidities and treatment. The following six fibrinolytic system indicators were examined once in each study participant (patient or control): plasminogen level (\%), tissue plasminogen activator level (t-PA level) (ng/mL), plasminogen activator inhibitor type 1 activity (PAI-1 activity) (AU/mL), $\alpha 2$-antiplamine activity (\%), vitronectin $(\mathrm{mcg} / \mathrm{mL})$ and D-dimer plasma levels (mg/L).

A number of diseases, conditions, and medications that alter hemostasis were identified as exclusion criteria. They were identical for patient and control groups. Thus, our aim was to maximize the 'net' effect of the arrhythmia itself on the fibrinolytic system.

Exclusion criteria:

1. cardiovascular diseases: ischemic heart disease, heart failure, high-grade and/or uncontrolled hypertension, moderate or severe acquired valve defects, cardiomyopathy, implanted device for the treatment of rhythm-conduction disorders, inflammatory heart disease, congenital heart diseases;

2. other diseases: kidney or liver failure, inflammatory and/or infectious diseases, neoplastic and autoimmune diseases, chronic pulmonary insufficiency, endocrine disorders (except for non-insulin dependent, well-controlled DM type 2); previous thromboembolic incidents, bleeding diathesis, miscarriages (for women);

3. intake of hormone replacement therapy, contraceptives, oral anticoagulants or antiplatelet drugs, pregnancy, systemic intake of analgesics (incl. NSAIDs), obesity with BMI >35;

4. unsuccessful restoration of sinus rhythm with drugs (propafenone) (for the patient group).

Blood sample collection and laboratory procedures

The fibrinolytic parameters were examined in peripheral venous blood. The samples were collected, centrifuged and the resulting citrate plasma stored according to the requirements of the tests used, which have been described in detail elsewhere by us [10]. The indicators were determined using colorimetric and enzyme-linked immunosorbent assays [10].

\section{Statistical modeling approach}

Logistic regression model

Logistic regression is typically used when the predictor variables are not normally distributed and some may be categorical [12], [13]. Spatial prediction is modeled by a dependent variable and a number of independent variables that are available in a spatially continuous fashion across patients and controls.

Logistic regression is similar to multiple regression. However, the primary difference is that the dependent variable in the logistic regression is sampled as a binary variable (i.e. presence/ absence of PAF). 
The logistic regression therefore models the probability of presence and absence, given the observed values of predictor variables. Logistic regression fits a special s-shaped curve by taking a linear regression that may produce any $y$-value between $-\infty$ and $+\infty$, and transforming it with the function that produces a probability (p-probability) between 0 (as y approaches minus infinity) and 1 (as y approaches plus infinity).

$$
\text { (1) } p(y=1 / x)=\frac{\exp \left(\beta_{0}+\beta_{1} x\right)}{1+\exp \left(\beta_{0}+\beta_{1} x\right)} \text {. }
$$

In the logistic regression model, $\mathrm{x}$ is the data vector for a randomly selected experimental unit, is the coefficient of the independent variable, and $\mathrm{y}$ is the value of the binary outcome variable. The maximum likelihood method may be used to estimate $\beta_{0}$ and $\beta_{1}$.

The output of a statistically based model is an equation that can be used for prediction or estimation. Other outputs of the logistic model are odds ratio (OR), classification of cases in the decision matrix (Table-I) and accuracy of the prediction.

Table- I: Decision matrix

\begin{tabular}{|l|l|l|l|}
\hline \multirow{2}{*}{$\begin{array}{l}\text { Actual } \\
\text { State }\end{array}$} & \multicolumn{3}{|c|}{ Test Result (Diagnosis) } \\
\cline { 2 - 4 } & Positive $(T+)$ & Negative $(T+)$ & Rate correct \\
\hline $\begin{array}{l}\text { Positi- } \\
\text { ve (D +) }\end{array}$ & $\begin{array}{l}\text { True positive } \\
(\mathrm{TP})\end{array}$ & $\begin{array}{l}\text { False negative } \\
(\mathrm{FN})\end{array}$ & $\begin{array}{l}\mathrm{TPR}= \\
\mathrm{TP} /(\mathrm{TP}+\mathrm{FN})\end{array}$ \\
\hline $\begin{array}{l}\text { Negative } \\
(\mathrm{D}-)\end{array}$ & $\begin{array}{l}\text { False positive } \\
\text { (FP) }\end{array}$ & $\begin{array}{l}\text { True negative } \\
(\mathrm{TN})\end{array}$ & $\mathrm{FPR}=$ \\
$\mathrm{FP} /(\mathrm{FP}+\mathrm{TN})$
\end{tabular}

The rates of actually positive cases and of actually negative cases are the so called True Positive Rate (TPR) and False Positive Rate (FPR).

The formulas for calculating OR and accuracy of the model are given in (2) and (3) respectively:

$$
\mathrm{OR}=(\mathrm{TP} \times \mathrm{TN}) /(\mathrm{FN} \times \mathrm{FP})
$$

$$
\text { Accuracy of the model }=T P R \cdot P(D+)+F P R \cdot P(D-)
$$

Odds ratio is a statistic that quantifies the strength of the association between two events. OR is used to figure out if a particular indicator (e.g. plasminogen level) is a predictor for a particular outcome (absence of PAF), and to compare the various indicators for that outcome.

Regarding the diagnostic problem, using the estimated logistic model, one may say that prognosis is positive (absence of PAF) if $p(y=1 / x)>0.5$ and negative if the probability $p(y=1 / x) \leq 0,5$. The abscissa corresponding to 0.5 probability is the inflection point of the probability function (1), which is given by $x^{*}=\beta_{0} /\left(-\beta_{1}\right)$. For more precise diagnostic decisions, ROC analysis must be used.

The prevalence of the disease in the population subjected to the diagnostic test (or for which diagnoses are to be made) can be represented by $\mathrm{P}(\mathrm{D}+)=p(y=1 / x)$, the prior probability of the actual presence of the disease in a case from the observed population. Similarly, $P(D-)=1-P(D+)$ represents the prior probability that the disease is actually absent in a case from the observed population.

The limitations of diagnostic "accuracy" as a measure of decision performance require introduction of the concepts of "sensitivity" and "specificity" of a diagnostic test. These measures and the related indices, "true positive rate" and "false positive rate", are more meaningful than "accuracy," yet do not provide a unique description of diagnostic performance because they depend on the arbitrary selection of a decision threshold. The receiver operating characteristic (ROC) curve is shown to be a simple, yet complete empirical description of this decision threshold effect, indicating all possible combinations of the relative frequencies of the various kinds of correct and incorrect decisions.

\section{Receiver Operating Characteristic (ROC) curves}

ROC curve analysis is a commonly used method for assessing the accuracy of a diagnostic test [14]. ROC curves provide a diagnostic that may be used to distinguish between two classes of events and visualize classifier performance.

In ROC analysis, TPR is called Sensitivity (Se) of the model: $\mathrm{Se}=\mathrm{TPR}=\mathrm{TP} /(\mathrm{TP}+\mathrm{FN})$. Another characteristic of the model is the so-called Specificity (Sp): $\mathrm{Sp}=\mathrm{TN} /(\mathrm{TN}+\mathrm{FP})$. Let us emphasize that FPR=1-Sp.

The ROC curve is a plot of the probability of having a true positive rate i.e. Sensitivity versus the probability of a false positive rate FPR (falsely predicted event response) i.e. (1Specificity) as the cut-off probability varies.

In dichotomous statistical modeling, such as logistic regression, ROC curves are very useful for evaluating the predictive accuracy of a chosen model. The predicted probabilities (from 0 to 1 ) generated by the logistic model can be viewed as a continuous indicator (cut-off value) to be compared to the observed binary response variable.

An ideal model would have an area equal to 1 because then $\mathrm{P}$ (true positive) $=1$ and $\mathrm{P}$ (false positive) $=0$, regardless of the cut-off point. Each point on the ROC curve may be associated with a specific decision criterion for how much risk the user is willing to take regarding the accuracy of the prediction. This point will vary among observers because their decision criteria may vary even when their ROC curves are the same. Three criteria are used to find the optimal threshold point from a ROC curve [15]. First two methods give equal weight to sensitivity and specificity and impose no ethical, cost, and prevalence constraints. The third criterion considers cost which mainly includes financial cost for correct and false diagnosis, cost of discomfort to a person caused by treatment, and cost of further investigation when needed. This method is rarely used in medical literature because it is difficult to estimate the respective costs and prevalence is often difficult to assess.

These three criteria are known as points on curve closest to the point with coordinates $(0,1)$, Youden index, and minimize cost criterion, respectively. We use the second, Youden index, that maximizes the vertical distance from the line of equality to the point $(x, y)$. The $x$ represents (1-specificity) and $y$ represents sensitivity. In other words, the Youden index $(\mathrm{J})$ is the point on the ROC curve which is farthest from the line of equality (diagonal line, which connects the points $(0,0)$ and $(1,1)$ ). The main aim of the Youden index is to maximize the difference between TPR (Se) and FPR= $(1-S p)$ and little algebra yields $J=\max ($ Se-Sp). The value of $\mathrm{J}$ for a continuous test can be located by doing a search of plausible values where the sum of sensitivity and specificity can be maximum. 
The Youden index is a more commonly used criterion because this index reflects the intention to maximize the correct classification rate and is easy to calculate. Area under the ROC curve (AUC) does not contain information about sensitivity and specificity. The best method available to test the significance of apparent differences between measured ROC curves for different factors is to test the differences between areas under the curves fitted by the maximum likelihood procedure.

\section{RESULTS AND DISCISSION}

Plasminogen level, t-PA level, PAI-1 activity, $\alpha 2$-antiplasmin activity, vitronectin and D-dimer plasma levels were taken as predictors for the absence/presence of PAF in the constructed logistic models.

All analyses were performed using data analysis software STATISTICA 13.3.0, StatSoft Inc, USA package [16].

The positive outcome in our regression models was the absence of PAF. Using the Wald test, all six factors were identified as statistically significant predictors for the absence of PAF. The estimated parameters of the logistic functions (1) are given in the Table-II.

Table-II. Estimators of the parameters of univariate logistics models for association between fibrinolytic factors and the absence of PAF manifestation.

\begin{tabular}{|l|c|c|c|c|}
\hline Factor & $\begin{array}{c}\beta_{0} \\
\text { p-value }\end{array}$ & $\begin{array}{c}\beta_{1} \\
\text { p-value }\end{array}$ & $\begin{array}{l}\text { Odds } \\
\text { ratio }\end{array}$ & $\begin{array}{c}\text { Accuracy } \\
\text { (\%) }\end{array}$ \\
\hline $\begin{array}{l}\text { Plasminogen } \\
\text { level }\end{array}$ & $\begin{array}{c}10.354 \\
<0.001\end{array}$ & $\begin{array}{c}-0.083 \\
<0.001\end{array}$ & 17.875 & 80.58 \\
\hline t-PA level & $\begin{array}{c}8.835 \\
<0.001\end{array}$ & $\begin{array}{c}-1.034 \\
<0.001\end{array}$ & 12.114 & 77.67 \\
\hline PAI-1 activity & -9.450 & 0.885 & 34.554 & 85.44 \\
& $<0.001$ & $<0.001$ & & \\
\hline D-dimer & 0.753 & -1.806 & 2.236 & 57.84 \\
& $<0.029$ & $<0.015$ & & \\
\hline Vitronectin & -11.04 & 5.741 & 76.444 & 88.35 \\
& $<0.001$ & $<0.001$ & & \\
\hline$\alpha 2-$ antiplasmin & -2.772 & 0.023 & 4.042 & 66.67 \\
acivity & $<0.013$ & 0.011 & & \\
\hline
\end{tabular}

The graph of the estimated logistic regression model (values of probability function) for plasminogen level is given in Fig.1.

The estimated negative model parameter $\beta_{1}=-0.083$ for plasminogen level indicated that the higher the values of these levels, the lower the probability for the absence of PAF. Regarding the diagnostic problem: when using the estimated logistic model, the inflection point was $x^{*}=10.354 / 0.083=124.75 \%$ and the decision was that for the patients with plasminogen level higher than $124.75 \%$ prognosis was for the presence of PAF.

For a more precise decision, ROC analysis was used.

In our ROC analysis, the "positive" category were patients without PAF manifestation and "negative" category - patients with PAF manifestation. The ROC curve of plasminogen level is shown in Fig. 2.

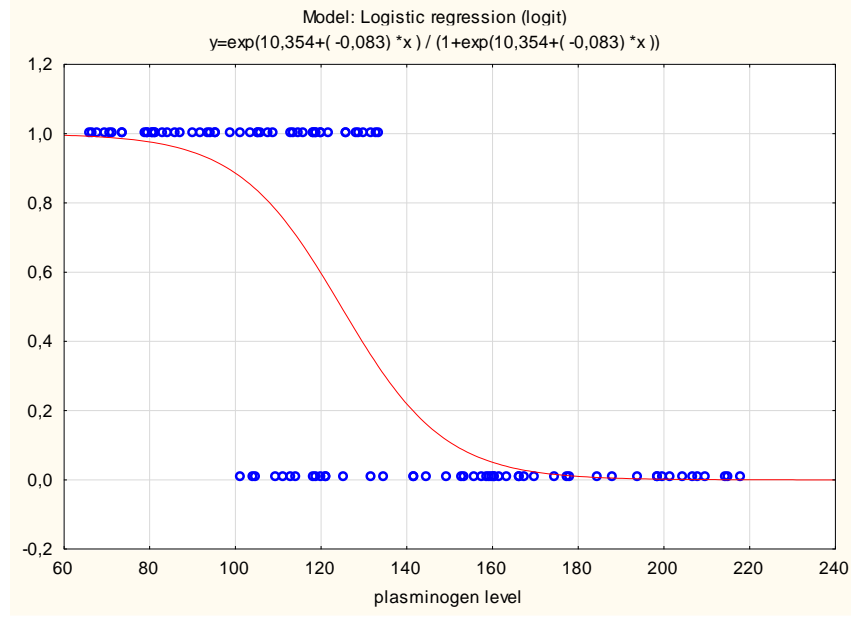

Fig. 1. Estimated probability function (red line) for absence of PAF manifestation using levels of the factor Plasminogen level.

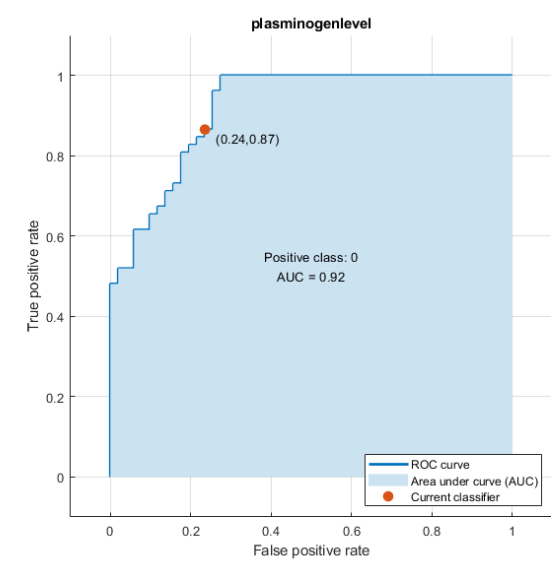

Fig. 2. ROC curve for diagnostic test of absence of PAF using values of the factor Plasminogen level.

AUC of the plasminogen level ROC curve was 0.92, i.e. the model was excellent. The optimal cut-off point of plasminogen level had the coordinates $(0.24,0.87)$, i.e. $\mathrm{Se}=0.87$ and $\mathrm{Sp}=0.76 .87 \%$ sensitivity means that $87 \%$ of the patients without PAF manifestation will be truly diagnosed as patients without PAF. $76 \%$ specificity means that $76 \%$ of the patients with PAF will be diagnosed as patients with PAF.

The graph of the estimated logistic regression model (values of probability function) for Vitronectin is given in Fig. 3.

The estimated positive parameter $=0.057$ for vitronectin indicated that the higher the values of this levels, the higher the probability for the absence of PAF.

Regarding the diagnostic problem: when using the estimated logistic model, the inflection point was $\mathrm{x}^{*}=(-11.035) /(-0.057)=193.60 \mathrm{mcg} / \mathrm{mL}$ and the decision was that for the patients with vitronectin greater than 193.60 $\mathrm{mcg} / \mathrm{mL}$, prognosis was for the absence of PAF.

For a more precise decision, ROC analysis was used. Let us remember that for our ROC analysis, "positive" category were patients without PAF manifestation and "negative" category - patients with PAF manifestation. The ROC curve of vitronectin is given in Fig. 4.

Published By:

Blue Eyes Intelligence Engineering

\& Sciences Publication

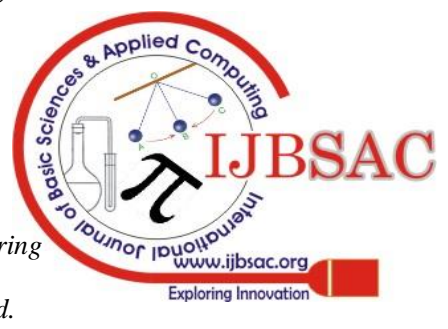




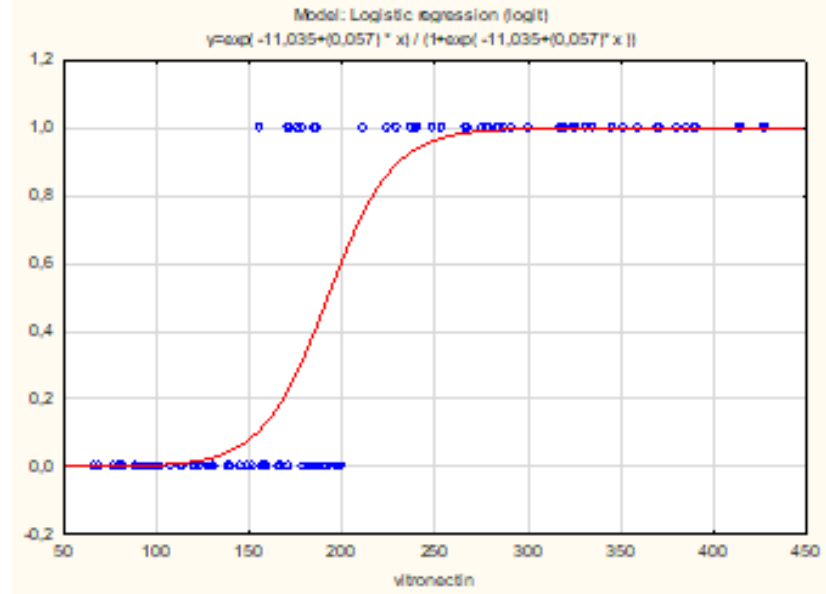

Fig. 3. Estimated probability function (red line) for absence of PAF manifestation using plasma level of vitronectin.

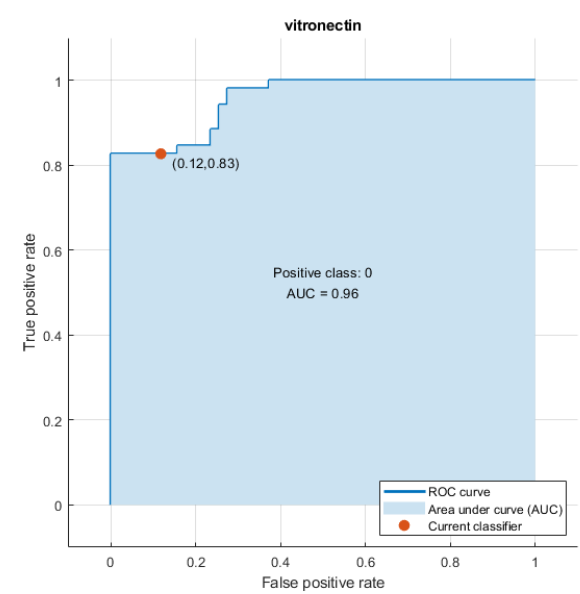

Fig. 4. ROC curve for the diagnostic value of vitronectin.

AUC of the vitronectin ROC curve is 0.96 , so this model is excellent, too. The optimal cut-off point of vitronectin had the coordinates $(0.12,0.83)$ i.e. $\mathrm{Se}=0.83$ and $\mathrm{Sp}=0.88 .83 \%$ sensitivity means that $83 \%$ of the patients without PAF manifestation will be truly diagnosed as patients without PAF. $88 \%$ specificity means that $88 \%$ of the patients with PAF will be diagnosed as patients with PAF.

The specificity and sensitivity of a diagnostic test and calculated AUC for all six fibrinolytic factors are given in Table-III.

As shown by the presented results, D-dimer plasma level had the poorest performance in terms of predictive ability to reject the presence of PAF, namely 37\% specificity, $81 \%$ sensitivity and AUC 0.56 (Table III, Fig. 5).

Table-III. Specificity, sensitivity and AUC of the evaluated fibrinolytic markers for ruling out PAF presence.

\begin{tabular}{|l|c|c|c|}
\hline \multicolumn{1}{|c|}{ Factor } & Specificity & Sensitivity & AUC \\
\hline $\begin{array}{l}\text { Plasminogen } \\
\text { level }\end{array}$ & 0.76 & 0.87 & 0.92 \\
\hline t-PA level & 0.75 & 0.81 & 0.92 \\
\hline PAI-1 activity & 0.86 & 0.87 & 0.95 \\
\hline D-dimer & 0.37 & 0.81 & 0.56 \\
\hline Vitronectin & 0.88 & 0.83 & 0.96 \\
\hline $\begin{array}{l}\alpha 2-\text { antiplasmin } \\
\text { acivity }\end{array}$ & 0.61 & 0.71 & 0.70 \\
\hline
\end{tabular}

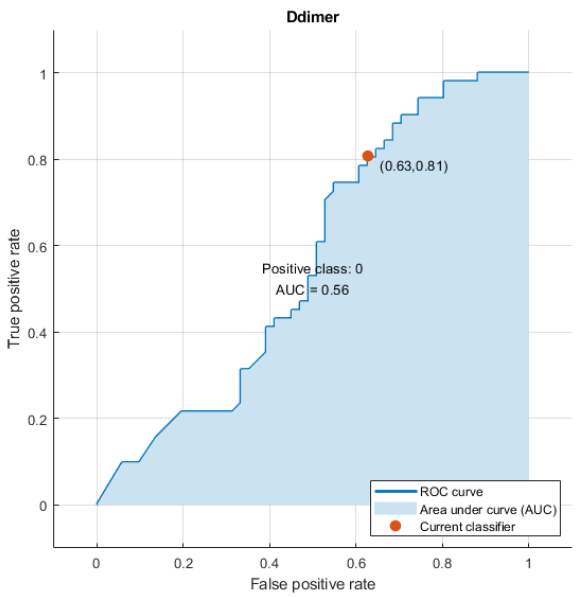

Fig. 5. ROC curve for diagnostic test of absence of PAF using values of the factor $\mathbf{D}$-dimer.

\section{CONCLUSION}

Biomarker diagnostics plays a key role in modern cardiology not only to confirm the diagnosis but also to exclude it. In many cases, rejecting the diagnosis is of even greater clinical and therapeutic importance. We believe this also applies to atrial fibrillation, which is the subject of our study. The use of tests that predict with great precision the absence of the disease significantly limits the possibility of false positive determination of atrial fibrillation.

In conclusion, the performed statistical modeling with logistic regression and ROC analysis showed that among the fibrinolytic system parameters studied by us, plasma levels of vitronectin were the most reliable indicator for the rejection of PAF, while the D-dimer had the lowest diagnostic value. Using these indicators could improve the identification of patients at embolic risk due to PAF, as well as assist in the choice of thromboprophylaxis.

\section{ACKNOWLEDGEMENT}

The first author Krasimira Prodanova is totally supported by project DN12/11/20.dec.2017 of the Ministry of Education and Science of Bulgaria for statistical analysis of data.

Conflicts of interest

No conflicts of interest to declare.

\section{REFERENCES}

1. Zoni-Berisso M, Lercari F, Carazza T, Domenicucci S. Epidemiology of atrial fibrillation: European perspective. Clin Epidemiol. 2014;6:213-20.

2. Quirino G, Giammaria M, Corbucci G, Pistelli P, Turri E, Mazza A et al. Diagnosis of paroxysmal atrial fibrillation in patients with implanted pacemakers: relationship to symptoms and other variables. Pacing Clin Electrophysiol. 2009;32(1):91-98.

3. Primo J, Gonçalves H, Macedo A, Russo P, Monteiro T, Guimarães J, Costa O. Prevalence of paroxysmal atrial fibrillation in a population assessed by continuous 24-hour monitoring. Rev Port Cardiol. 2017;36(7-8):535-546

4. Banerjee A, Taillandier S, Olesen JB, Lane DA, Lallemand B, Lip GY, Fauchier L. Pattern of atrial fibrillation and risk of outcomes: the Loire Valley Atrial Fibrillation Project. Int $\mathrm{J}$ Cardiol. 2013;167(6):2682-7.

5. Inoue $\mathrm{H}$, Atarashi $\mathrm{H}$, Okumura K, Yamashita T, 
Kumagai N, Origasa H. Thromboembolic events in paroxysmal vs. permanent non-valvular atrial fibrillation. Subanalysis of the J-RHYTHM Registry. Circ J. 2014;78(10):2388-93.

6. Disertori M, Franzosi MG, Barlera S, Cosmi F, Quintarelli S, Favero C et al; GISSI-AF investigators. Thromboembolic event rate in paroxysmal and persistent atrial fibrillation: data from the GISSI-AF trial. BMC Cardiovasc Disord. 2013;13:28.

7. Paciaroni M, Angelini F, Agnelli G, Tsivgoulis G, Furie KL, Tadi P et al. Early recurrence in paroxysmal versus sustained atrial fibrillation in patients with acute ischaemic stroke. Eur Stroke J. 2019;4(1):55-64.

8. Christensen LM, Krieger DW, Højberg S, et al. Paroxysmal atrial fibrillation occurs often in cryptogenic ischaemic stroke. Final results from the SURPRISE study. Eur J Neurol. 2014;21:884-889.

9. Wohlfahrt J, Stahrenberg R, Weber-Krüger M, et al. Clinical predictors to identify paroxysmal atrial fibrillation after ischaemic stroke. Eur J Neurol. 2014;21:21-27.

10. Negreva M, Georgiev S, Vitlianova K. Early effects of paroxysmal atrial fibrillation on plasma markers of fibrinolysis. Medicine (Baltimore).2016;95(45):e5184.

11. World Medical Association Declaration of Helsinki (2008). Ethical principles for medical research involving human subjects. 59th WMA General Assembly. Seoul.

12. Hosmer DW, Lemeshow S, Sturdivant R. Applied Logistic Regression, 3rd Edition, New York: Wiley and Sons, 2013, pp 8-20.

13. Johnson D E. Applied Multivariate Methods for Data Analysis. Belmont, CA: Duxbury Press, 1998.

14. Williams CJ, Lee SS, Fisher RA, Dickerman LH (1999) A comparison of statistical methods for prenatal screening for Down syndrome. Appl Stoch Model Data Anal 15:89-101.

15. Fluss R, Faraggi D, Reiser B. Estimation of the Youden Index and its associated cutoff point.Biom J. 2005;47(4):458-72.

16. TIBCO Statistica ${ }^{\mathrm{TM}}$ Release Notes. Software Release 13.3.0. June 2017

\section{AUTHORS PROFILE}

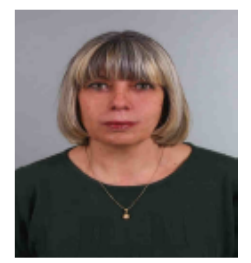

Prof. Krasimira Prodanova, PhD Personal details: 1972 - 1976 BSc (Faculty of Mathematics, Informatics and Mechanics) University of Sofia, Bulgaria; 1976 - 1978 MSc (Differential Geometry) University of Sofia, Bulgaria; 1995 - PhD (Theory of Probability and Statistcs - thesis title: Statistical Models in pharmacokinetics) University of Sofia, Bulgaria. Employment history and experiences: 2007 - present; Previous Appointments: 1980-1987 Senior Biostatisticians (Bulgarian Academy of Medicine, Faculty of Pharmacy); 1987-1999: Assistant Professor (TU-Sofia, Faculty of Applied Mathematics\&Informatics, Department of Statistics\& Optimization); 2000Present: Professor; 2000 - 2004: Head of Department "Statistics \& Optimization". Scientific Publications: above 9, more of them with Impact Factor; Research Interests include mathematical modeling in pharmacokinetics and medicine, estimation of the parameters of stochastic models, drug response models, survival analysis and optimization problems.

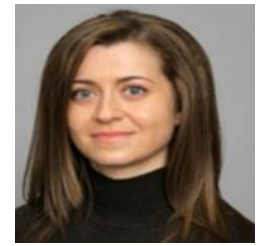

Assoc. Prof. Mariya Negreva, MD, PhD graduated from Medical University of Varna,Bulgaria in 2006. Since 2008 Negreva has been working as assistant professor in Intensive Care Unit at University hospital of Varna, Bulgaria; since 2013 has been a specialist in cardiology and echocardiography. In 2015 completed her PhD. 2016 - present assoc. prof. in First clinic of cardiology, University hospital of Varna, Bulgaria. Her research area is atrial fibrillation and echocardiography. Member Of Bulgarian Society Of Cardiology, Euripean Society of Cardiology.

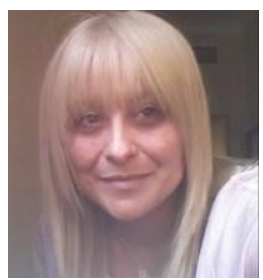

Katerina Vitlianova, PhD, DSc Education: Higher medical education - Medical University of Varna, Bulgaria (1992), Master of Phylosophy degree in Epidemiology and Biostatistics Cambridge University, UK 1993, Specialities in Internal Medicine (2000) and Cardiology (2008) Medical University of Sofia, Specialisation in Echocardiography and Emergency medicine Barzilai Medical Center, Ben-Gurion University of Negev, Israel.Research interests mainly in the fields of Heart failure, biomarkers,myocardial infarction ant rrhythm disorders. Memberships: Bulgarian Society of Cardiology, Chairmen of the working group of Women and cardiovascular risk, Bulgarian League of Hypertension, Balkan Medical 